\title{
Gambaran Fungsi Kognitif pada Pasien Epilepsi di Poliklinik Saraf RSUP Prof. Dr. R.D. Kandou Manado
}

\author{
${ }^{1}$ Raymond J. Sigar \\ ${ }^{2}$ Mieke A. H. N. Kembuan \\ ${ }^{2}$ Corry N. Mahama
}

\begin{abstract}
${ }^{1}$ Program Studi Pendidikan Dokter Fakultas Kedokteran Universitas Sam Ratulangi Manado
${ }^{2}$ Bagian Neurologi Fakultas Kedokteran Universitas Sam Ratulangi Manado

Raymond.Jonathan.Sigar@gmail.com
\end{abstract}

\begin{abstract}
Epilepsy is one of most common neurological disorders that causes cognitive decline. This stuayd was aimed to ascertain the overview of cognitive function in epilepsy patients at the Neurology Clinic of Prof Dr. R. D. Kandou Hospital Manado. This was a prospective descriptive study with a cross-sectional design. Data were obtained through anamnesis and direct test to 35 epileptic patients by using questionnaire, MMSE, and Ina-MoCA instruments in the Neurology Clinic of Prof. Dr. R. D. Kandou Hospital Manado from October to November 2017. The results MMSE showed $77.10 \%$ of patients had normal cognitive function. Meanwhile, the Ina-MoCa resulted in $89 \%$ of respondents suffering from cognitive decline. Conclusion: There were impaired cognitive functions ranging from mild to severe in epileptic patients that could affect their quality of life and functional status.
\end{abstract}

Keywords: epilepsy, cognitive function

\begin{abstract}
Abstrak: Epilepsi adalah salah satu gangguan neurologik yang terbanyak yang menyebabkan gangguan fungsi kognitif. Penelitian ini bertujuan untuk mengetahui gambaran fungsi kognitif pada pasien epilepsi di Poliklinik Saraf RSUP Prof. Dr. R. D. Kandou Manado. Jenis penelitian ialah deskriptif prospektif dengan desain potong-lintang. Pengumpulan data diperoleh melalui wawancara dan pengujian langsung terhadap pasien epilepsy yang berjumlah 35 orang. Penelitian ini menggunakan kuesioner, serta instrumen MMSE dan Ina-MoCA dilakukan di Poliklinik Saraf RSUP Prof Dr. R. D. Kandou Manado sejak bulan Oktober s/d November 2017. Hasil pemeriksaan dengan MMSE menunjukkan $77,10 \%$ dari pasien dengan fungsi kognitif normal sedangkan pemeriksaan dengan Ina-MoCA menunjukkan $89 \%$ dari pasien mengalami gangguan fungsi kognitif. Simpulan: Terdapat gangguan fungsi kognitif ringan-berat pada pasien epilepsi yang dapat memengaruhi kualitas hidup dan status fungsional.
\end{abstract}

Kata kunci: epilepsi, fungsi kogntif

Epilepsi adalah salah satu gangguan neurologi yang terbanyak dan memengaruhi berbagai usia. ${ }^{1}$ Sekitar 50 juta orang di seluruh dunia menyandang epilepsi. ${ }^{2}$ Di RSUP Prof. Dr. R. D. Kandou Manado epilepsi termasuk dalam 10 penyakit terbanyak yang menduduki peringkat 1 dalam kategori pasien rawat jalan dengan jumlah 813 pasien. $^{3}$

Di berbagai bagian di dunia, orang dengan epilepsi (ODE) dan keluarganya menderita karena stigma yang negatif serta diskriminasi, yang pada akhirnya akan menyebabkan penghindaran sosial. ${ }^{4}$. Walau penyakit ini telah dikenal lama dalam masyarakat, terbukti dengan adanya istilahistlilah bahasa daerah untuk penyakit ini seperti sawan, ayan dan lain sebagainya, tetapi pengertian akan penyakit ini masih kurang bahkan salah, sehingga penyandang 
digolongkan dalam penyakit gila, kutukan dan, turunan yang berakibat penyandang epilepsi tidak diobati atau bahkan disembunyikan. ${ }^{5}$ Akibatnya banyak penderita epilepsi yang tidak terdiagnosis dan mendapat pengobatan yang tidak tepat sehingga menimbulkan dampak klinis dan psikososial yang merugikan baik penyandang maupun keluarganya, ${ }^{6}$ adanya gangguan tidur, perasaan rendah diri, kecemasan dan depresi. ${ }^{6-8}$ Beberapa studi telah menunjukkan pasien dengan epilepsi mempunyai beberapa gangguan kognitif tingkat tertentu, termasuk memori, atensi, visuospasial, fungsi ekskutif, abstraksi, dan kecepatan berpikir. ${ }^{9,10}$

Epilepsi yang terdiagnosis pada anak anak memengaruhi secara negatif perkembangan dan maturasi otak yang mengarah pada defisit kognitif. ${ }^{10}$ Anak dengan epilepsi aktif cenderung memiliki kesulitan akademik dan rendahnya capaian akademik yang nantinya akan memengaruhi status fungsional dan kualitas hidup ketika dewasa. $^{11,12}$

Epilepsi pada dewasa dan usia lanjut biasa dihubungkan dengan penyakit degeneratif dan proses penuaan yang turut melandasi memburuknya fungsi kognitif yang diakibatkan oleh epilepsi itu sendiri, bahkan beberapa pasien lebih mengeluhkan hendaya yang disebabkan fungsi kognitif dibandingkan penyakit bangkitan epilepsi itu sendiri. $^{13}$

Tingkat keparahan gangguan tergantung pada banyak faktor, yaitu: usia saat onset bangkitan, lokasi fokus bangkitan, sifat alami dari gangguan bangkitan, pengobatan dengan obat anti-epilepsi, faktor psikososial seperti status sosioekonomi dan rendahnya harga diri. Berbagai sindrom epilepsi, frekuensi gelombang paku pada EEG, dan penggunaan dari AED biasanya dihubungkan dengan gangguan kognitif. ${ }^{10-13}$

\section{METODE PENELITIAN}

Jenis penelitian ini ialah deskriptif prospektif dengan desain potong lintang yang dilaksanakan pada bulan OktoberNovember 2017 bertempat di Poliklinik
Neurologi RSUP Prof. Dr. R. D. Kandou Manado. Pengambilan sampel dilakukan secara consecutive sampling dengan menggunakan data primer melalui wawancara dan pengujian langsung terhadap pasien epilepsi yang berjumlah 35 orang yang memenuhi kriteria inklusi dengan menggunakan kuesioner, serta instrumen MMSE dan Ina-MoCA. Jumlah pasien dalam penelitian sesuai dengan jumlah seluruh pasien yang diperoleh pada bulan Oktober November 2017.

\section{HASIL PENELITIAN}

Pada penelitian ini terdapat 35 pasien penyandang epilepsi yang memenuhi kriteria penelitian.

\section{Karakteristik sampel penelitian}

Tabel 1 memperlihatkan bahwa jenis kelamin laki-laki lebih banyak menderita epilepsi dengan jumlah 27 pasien $(77,1 \%)$. Berdasarkan kategori usia, usia produktif yaitu 19-64 tahun merupakan yang terbanyak dengan jumlah 25 pasien $(71,4 \%)$. Berdasarkan pekerjaan, penyandang epilepsi yang tidak memiliki pekerjaan berjumlah 9 pasien $(25,7 \%)$.

Berdasarkan frekuensi bangkitan, frekuensi 1-10x bangkitan per bulan yang terbanyak dengan jumlah 13 pasien $(37,1 \%)$. Demikian pula pada durasi, didapatkan durasi $<1$ menit yang terbanyak dengan jumlah 13 pasien $(37,1 \%)$. Berdasarkan lama menyandang epilepsi didapatkan banyak kasus kronis dengan lama menyandang epilepsi $>6$ tahun sebanyak 19 pasien $(54,3 \%)$. Berdasarkan onset bangkitan, ditemukan bahwa pasien dengan onset umum merupakan kasus terbanyak dengan jumlah 20 pasien $(57,1 \%)$.

Berdasarkan diagnosis yang ditegakkan oleh spesialis saraf, diagnosis epilepsi sekunder lebih banyak dengan jumlah 20 pasien $(54,1 \%)$. Berdasarkan pengobatan yang diberikan pada penyandang epilepsi, banyak pasien yang menjalani pengobatan monoterapi dengan jumlah 24 pasien $(68,5 \%)$. 
Tabel 1. Karakteristik sampel penelitian

\begin{tabular}{|c|c|c|}
\hline Variabel & Jumlah (n) & $\begin{array}{c}\text { Persentase } \\
(\%)\end{array}$ \\
\hline \multicolumn{3}{|l|}{ Jenis kelamin } \\
\hline Laki - Laki & 27 & $77,1 \%$ \\
\hline Perempuan & 8 & $22,9 \%$ \\
\hline \multicolumn{3}{|l|}{ Usia } \\
\hline $14-18$ tahun & 8 & $22,9 \%$ \\
\hline $19-64$ tahun & 25 & $71,4 \%$ \\
\hline$>64$ tahun & 2 & $5,7 \%$ \\
\hline \multicolumn{3}{|l|}{ Tingkat Pendidikan } \\
\hline SD & 6 & $17.1 \%$ \\
\hline SMP & 7 & $20 \%$ \\
\hline SMA & 18 & $51.4 \%$ \\
\hline Sarjana & 4 & $11.4 \%$ \\
\hline \multicolumn{3}{|l|}{ Pekerjaan } \\
\hline Swasta & 2 & $5.7 \%$ \\
\hline Pensiunan & 3 & $8.6 \%$ \\
\hline IRT & 2 & $5.7 \%$ \\
\hline Pelajar & 6 & $17.1 \%$ \\
\hline Wiraswasta & 3 & $8.6 \%$ \\
\hline Petani & 2 & $5.7 \%$ \\
\hline Buruh & 4 & $11.4 \%$ \\
\hline Lainnya & 4 & $11.4 \%$ \\
\hline Tidak Bekerja & 9 & $25.7 \%$ \\
\hline \multicolumn{3}{|l|}{ Frekuensi } \\
\hline$<1 \mathrm{x}$ per bulan & 12 & $34.3 \%$ \\
\hline 1-10x per bulan & 13 & $37.1 \%$ \\
\hline$>10 x$ per bulan & 10 & $28.6 \%$ \\
\hline \multicolumn{3}{|l|}{ Durasi } \\
\hline$<1$ menit & 13 & $37.1 \%$ \\
\hline $1-5$ menit & 10 & $28.6 \%$ \\
\hline$>5$ menit & 12 & $34.3 \%$ \\
\hline \multicolumn{3}{|l|}{ Lama menyandang epilepsi } \\
\hline$<6$ tahun & 16 & $45.7 \%$ \\
\hline$>6$ tahun & 19 & $54.3 \%$ \\
\hline \multicolumn{3}{|l|}{ Onset } \\
\hline Fokal sadar & 5 & $14.3 \%$ \\
\hline Fokal gangguan kesadaran & 10 & $28.6 \%$ \\
\hline Umum & 20 & $57.1 \%$ \\
\hline \multicolumn{3}{|l|}{ Diagnosis } \\
\hline Epilepsi primer & 15 & $42.9 \%$ \\
\hline Epilepsi sekunder & 20 & $57.1 \%$ \\
\hline \multicolumn{3}{|l|}{ Pengobatan } \\
\hline Monoterapi & 24 & $68.5 \%$ \\
\hline Politerapi & 11 & $31.4 \%$ \\
\hline
\end{tabular}


Distribusi hasil MMSE penyandang epilepsi.

Berdasarkan hasil pemeriksaan MMSE, sebagian besar hasil menunjukkan fungsi kognitif yang normal pada semua variabel dan hanya sebagian kecil yang curiga maupun pasti gangguan fungsi kognitif (Tabel 2).

Tabel 2. Distribusi hasil MMSE penderita epilepsi.

\begin{tabular}{lcccccc}
\hline & \multicolumn{7}{c}{ MMSE } \\
\hline Variabel & \multicolumn{7}{c}{ Normal } & \multicolumn{2}{c}{$\begin{array}{c}\text { Curiga gangguan } \\
\text { fungsi kognitif }\end{array}$} & $\begin{array}{c}\text { Pasti gangguan } \\
\text { fungsi kognitif }\end{array}$ \\
\cline { 2 - 8 } & $\mathrm{n}$ & $\%$ & $\mathrm{n}$ & $\%$ & $\mathrm{n}$ & $\%$ \\
\hline Jenis kelamin & 20 & $74,1 \%$ & 5 & $18,5 \%$ & 2 & $7,4 \%$ \\
$\quad$ Laki - Laki & 7 & $87,5 \%$ & 1 & $12,5 \%$ & 0 & $0 \%$ \\
$\quad$ Perempuan & & & & & & \\
Usia & 6 & $75 \%$ & 2 & $25 \%$ & 0 & $0 \%$ \\
$\quad 14-18$ tahun & 19 & $76 \%$ & 4 & $16 \%$ & 2 & $8 \%$ \\
$\quad 19-64$ tahun & 2 & $100 \%$ & 0 & $0 \%$ & 0 & $0 \%$ \\
$>64$ tahun & & & & &
\end{tabular}

\section{Tingkat pendidikan}

SD

SMP

SMA

Sarjana

Pekerjaan

Swasta

Pensiunan

IRT

Pelajar

Wiraswasta

Petani

Buruh

Lainnya

Tidak Bekerja

Frekuensi

$<1 \mathrm{x}$ per bulan

1-10x per bulan

$>10 x$ per bulan

\section{Durasi}

$$
\begin{aligned}
& <1 \text { menit } \\
& 1-5 \text { menit } \\
& >5 \text { menit }
\end{aligned}
$$

Lama menyandang

$<6$ tahun

$>6$ tahun

$4 \quad 66,7 \% \quad 1$

$6 \quad 85,7 \%$

$14 \quad 77,8 \%$

$3 \quad 75 \%$

$2100 \% \quad 0$

$3 \quad 100 \% \quad 0$

$2100 \% \quad 0$

$\begin{array}{ccc}16,7 \% & 1 & 16,7 \% \\ 14,3 \% & 0 & 0 \% \\ 16,7 \% & 1 & 5,6 \% \\ 25 \% & 0 & 0 \%\end{array}$

$5 \quad 83,3 \% \quad 1$

$2 \quad 66,7 \% \quad 1$

$2100 \% \quad 0$

$4 \quad 100 \% \quad 0$

$3 \quad 75 \% \quad 1$

$4 \quad 44,4 \% \quad 3$

$9 \quad 75 \% \quad 3$

$12 \quad 92,3 \% \quad 0$

$6 \quad 60 \% \quad 3$

$\begin{array}{ll}9 & 69,2 \% \\ 9 & 90 \% \\ 9 & 75 \%\end{array}$

$14 \quad 87,5 \%$

$168,4 \% \quad 4$

$\begin{array}{ccc}0 \% & 0 & 0 \% \\ 0 \% & 0 & 0 \% \\ 0 \% & 0 & 0 \% \\ 16,7 \% & 0 & 0 \% \\ 33,3 \% & 0 & 0 \% \\ 0 \% & 0 & 0 \% \\ 0 \% & 0 & 0 \% \\ 25 \% & 0 & 0 \% \\ 33,3 \% & 2 & 22,2 \%\end{array}$

$\begin{array}{ccc}25 \% & 0 & 0 \% \\ 0 \% & 1 & 7,7 \% \\ 30 \% & 1 & 10 \%\end{array}$


Onset

\begin{tabular}{lcccccc}
$\begin{array}{l}\text { Fokal Sadar } \\
\text { Fokal Gangguan }\end{array}$ & 2 & $40 \%$ & 3 & $60 \%$ & 0 & $0 \%$ \\
$\quad \begin{array}{l}\text { Kesadaran } \\
\text { Umum }\end{array}$ & 9 & $90 \%$ & 0 & $0 \%$ & 1 & $10 \%$ \\
$\begin{array}{l}\text { Diagnosis } \\
\quad \text { Epilepsi primer }\end{array}$ & 16 & $80 \%$ & 3 & $15 \%$ & 1 & $5 \%$ \\
$\quad \begin{array}{l}\text { Epilepsi sekunder } \\
\text { Pengobatan }\end{array}$ & 15 & $75 \%$ & 3 & $20 \%$ & 0 & $0 \%$ \\
$\quad$ Monoterapi & 21 & $87,5 \%$ & 3 & $12,5 \%$ & 0 & $0 \%$ \\
$\quad$ Politerapi & 6 & $54,5 \%$ & 3 & $27,3 \%$ & 2 & $18,2 \%$ \\
\hline
\end{tabular}

\section{Distribusi domain kognitif berdasarkan MMSE}

Berdasarkan Tabel 3 didapatkan bahwa pasien dengan onset umum yang paling menunjukkan penurunan fungsi kognitif dengan komponen terbanyak ialah memori sebanyak 9 orang $(33,3 \%)$, diikuti gangguan atensi dan kalkulasi (26\%), gangguan orientasi (22\%), gangguan bahasa $(18,5 \%)$, dan tidak adanya gangguan registrasi.

Tabel 3. Distribusi domain kognitif berdasarkan MMSE

\begin{tabular}{lcccccc}
\hline Penurunan fungsi kognitif & \multicolumn{2}{c}{ Umum } & $\begin{array}{c}\text { Fokal dengan gang- } \\
\text { guan kesadaran }\end{array}$ & $\begin{array}{c}\text { Fokal tanpa gang- } \\
\text { guan kesadaran }\end{array}$ \\
\cline { 2 - 7 } & $\mathbf{n}$ & $\%$ & $\mathbf{n}$ & $\%$ & $\mathbf{n}$ & $\%$ \\
Orientasi & 6 & $22 \%$ & 1 & $8,3 \%$ & 1 & $9,1 \%$ \\
Registrasi & 0 & $0 \%$ & 1 & $8,3 \%$ & 0 & $0 \%$ \\
Atensi dan kalkulasi & 7 & $26 \%$ & 2 & $16,7 \%$ & 3 & $27,3 \%$ \\
Mengingat kembali & 9 & $33,3 \%$ & 5 & $41,7 \%$ & 3 & $27,3 \%$ \\
Bahasa & 5 & $18,5 \%$ & 3 & $25 \%$ & 3 & $27,3 \%$ \\
\hline
\end{tabular}

\section{Distribusi hasil Ina-MoCA penyandang epilepsi}

Berdasarkan hasil pemeriksaan InaMoCA (Tabel 4), pada kategori jenis kelamin laki-laki terdapat 11 pasien $(40,7 \%)$ dengan hasil gangguan fungsi kognitif ringan dan 11 pasien lainnya dengan hasil gangguan fungsi kognitif sedang.

Berdasarkan usia, kelompok usia 19-64 tahun mengalami gangguan fungsi kognitif sedang dengan jumlah 11 pasien (44\%). Berdasarkan tingkat pendidikan, SMA merupakan yang teratas berjumlah 7 pasien $(38,9 \%)$ dengan gangguan fungsi kognitif ringan dan 6 pasien $(33,3 \%)$ dengan gangguan fungsi kognitif sedang. Berda- sarkan pekerjaan, pasien yang sudah tidak memliki pekerjaan mengalami gangguan fungsi kognitif sedang dengan jumlah 15 pasien $(42,9 \%)$ dan 14 pasien $(40 \%)$ dengan gangguan fungsi kognitif ringan.

Berdasarkan frekuensi, terdapat 7 pasien (70\%) dengan jumlah bangkitan $>10 \mathrm{x}$ mengalami gangguan fungsi kognitif sedang. Berdasarkan durasi, 6 pasien $(60 \%)$ dengan durasi 1-5 menit mengalami gangguan fungsi kognitif ringan. Berdasarkan lamanya menyandang epilepsi, lama menderita $>6$ tahun yang mengalami gangguan fungsi kognitif ringan dan sedang masing-masing sebanyak 8 pasien $(42,1 \%)$. Berdasarkan onset, sebanyak 7 pasien (35\%) dengan bangkitan umum mengalami 
gangguan fungsi kognitif sedang.

Berdasarkan diagnosis, pasien dengan epilepsi primer yang mengalami gangguan fungsi kognitif sedang sebanyak 8 pasien $(53,3 \%)$, demikian pula pada pasien epilepsi sekunder yang mengalami gangguan fungsi kognitif ringan. Berdasarkan pengobatan, didapati 12 pasien (50\%) dengan pengobatan monoterapi mengalami gangguan fungsi kognitif ringan.

\section{Distribusi domain kognitif berdasarkan Ina-MoCA}

Berdasarkan tabel 5, didapatkan onset umum yang paling menunjukkan penurunan fungsi kognitif, dengan komponen yang terbanyak adalah gangguan memori (delayed recall) sebanyak 16 orang (22\%), diikuti dengan gangguan visuospasial/ eksekutif 15 orang (21\%), atensi dan bahasa $(13 \%)$.

Tabel 4. Distribusi hasil Ina-MoCA penderita epilepsi

\begin{tabular}{|c|c|c|c|c|c|c|c|c|}
\hline \multirow{2}{*}{ Variabel } & \multicolumn{2}{|c|}{ Normal } & \multicolumn{2}{|c|}{$\begin{array}{c}\text { Ina-MoCA } \\
\text { Gangguan fungsi } \\
\text { kognitif ringan }\end{array}$} & \multicolumn{2}{|c|}{$\begin{array}{l}\text { Gangguan fungsi } \\
\text { kognitif sedang }\end{array}$} & \multicolumn{2}{|c|}{$\begin{array}{c}\text { Gangguan fungsi } \\
\text { kognitif Berat }\end{array}$} \\
\hline & n & $\%$ & n & $\%$ & $\mathbf{n}$ & $\%$ & $\mathbf{n}$ & $\%$ \\
\hline \multicolumn{9}{|l|}{ Jenis kelamin } \\
\hline Laki - Laki & 3 & $11,1 \%$ & 11 & $40,7 \%$ & 11 & $40,7 \%$ & 2 & $7,4 \%$ \\
\hline Perempuan & 1 & $12,5 \%$ & 3 & $37,5 \%$ & 4 & $50 \%$ & 0 & $0 \%$ \\
\hline \multicolumn{9}{|l|}{ Usia } \\
\hline $14-18$ tahun & 0 & $0 \%$ & 5 & $62,5 \%$ & 3 & $37,5 \%$ & 0 & $0 \%$ \\
\hline $19-64$ tahun & 4 & $16 \%$ & 8 & $32 \%$ & 11 & $44 \%$ & 2 & $8 \%$ \\
\hline$>64$ tahun & 0 & $0 \%$ & 1 & $50 \%$ & 1 & $50 \%$ & 0 & $0 \%$ \\
\hline \multicolumn{9}{|l|}{ Tingkat Pendidikan } \\
\hline $\mathrm{SD}$ & 0 & $0 \%$ & 1 & $16,7 \%$ & 4 & $66,7 \%$ & 1 & $16,7 \%$ \\
\hline SMP & 0 & $0 \%$ & 5 & $71,4 \%$ & 2 & $28,6 \%$ & 0 & $0 \%$ \\
\hline SMA & 4 & $22,2 \%$ & 7 & $38,9 \%$ & 6 & $33,3 \%$ & 1 & $5,6 \%$ \\
\hline Sarjana & 0 & $0 \%$ & 1 & $25 \%$ & 3 & $75 \%$ & 0 & $0 \%$ \\
\hline \multicolumn{9}{|l|}{ Pekerjaan } \\
\hline Swasta & 1 & $50 \%$ & 0 & $0 \%$ & 1 & $50 \%$ & 0 & $0 \%$ \\
\hline Pensiunan & 0 & $0 \%$ & 1 & $33 \%$ & 2 & $66,7 \%$ & 0 & $0 \%$ \\
\hline IRT & 1 & $50 \%$ & 1 & $50 \%$ & 0 & $0 \%$ & 0 & $0 \%$ \\
\hline Pelajar & 0 & $0 \%$ & 4 & $66,7 \%$ & 2 & $33,3 \%$ & 0 & $0 \%$ \\
\hline Wiraswasta & 0 & $0 \%$ & 3 & $100 \%$ & 0 & $0 \%$ & 0 & $0 \%$ \\
\hline Petani & 1 & $50 \%$ & 0 & $0 \%$ & 1 & $50 \%$ & 0 & $0 \%$ \\
\hline Buruh & 1 & $25,0 \%$ & 2 & $50 \%$ & 1 & $25 \%$ & 0 & $0 \%$ \\
\hline Lainnya & 0 & $0 \%$ & 1 & $25 \%$ & 3 & $75 \%$ & 0 & $0 \%$ \\
\hline Tidak bekerja & 0 & $0 \%$ & 2 & $22 \%$ & 5 & $55,6 \%$ & 2 & $22,2 \%$ \\
\hline \multicolumn{9}{|l|}{ Frekuensi } \\
\hline$<1 \mathrm{x}$ per bulan & 3 & $25 \%$ & 5 & $41,7 \%$ & 4 & $33,3 \%$ & 0 & $0 \%$ \\
\hline 1-10x per bulan & 1 & $7,7 \%$ & 7 & $53,8 \%$ & 4 & $30,8 \%$ & 1 & $7,7 \%$ \\
\hline$>10 x$ per bulan & 0 & $0 \%$ & 2 & $20 \%$ & 7 & $70 \%$ & 1 & $10 \%$ \\
\hline \multicolumn{9}{|l|}{ Durasi } \\
\hline$<1$ menit & 1 & $7,7 \%$ & 4 & $30,8 \%$ & 8 & $61,5 \%$ & 0 & $0 \%$ \\
\hline $1-5$ menit & 1 & $10 \%$ & 6 & $60 \%$ & 3 & $30 \%$ & 0 & $0 \%$ \\
\hline$>5$ menit & 2 & $16,7 \%$ & 4 & $33,3 \%$ & 4 & $33,3 \%$ & 2 & $16,7 \%$ \\
\hline
\end{tabular}




\section{Lama menyandang}

$\begin{array}{ccccccccc}<6 \text { tahun } & 3 & 18,8 \% & 6 & 37,5 \% & 7 & 43,8 \% & 0 & 0 \% \\ >6 \text { tahun } & 1 & 5,3 \% & 8 & 42,1 \% & 8 & 42,1 \% & 2 & 10,5 \%\end{array}$

\section{Onset}

$\begin{array}{lrrrrrrrr}\text { Fokal sadar } & 0 & 0 \% & 1 & 20 \% & 4 & 80 \% & 0 & 0 \% \\ \text { Fokal gangguan } & 1 & 10 \% & 4 & 40 \% & 4 & 40 \% & 1 & 10 \% \\ \text { kesadaran } & 3 & 15 \% & 9 & 45 \% & 7 & 35 \% & 1 & 5 \% \\ \text { Umum } & & & & & & & \end{array}$

Diagnosis

$\begin{array}{lcccccccc}\text { Epilepsi primer } & 1 & 6,7 \% & 6 & 40 \% & 8 & 53,3 \% & 0 & 0 \% \\ \text { Epilepsi sekunder } & 3 & 15 \% & 8 & 40 \% & 7 & 35 \% & 2 & 10 \%\end{array}$

Pengobatan

$\begin{array}{lllllllll}\text { Monoterapi } & 4 & 16,7 \% & 12 & 50 \% & 8 & 33 \% & 0 & 0 \%\end{array}$

\begin{tabular}{lllllllll} 
Politerapi & 0 & $0 \%$ & 2 & $18,2 \%$ & 7 & $63,6 \%$ & 2 & $18,2 \%$ \\
\hline
\end{tabular}

Tabel 5. Distribusi domain kognitif berdasarkan Ina-MoCA

\begin{tabular}{ccccccc}
\hline Penurunan fungsi kognitif & Umum & \multicolumn{2}{c}{$\begin{array}{c}\text { Fokal dengan } \\
\text { gangguan } \\
\text { kesadaran }\end{array}$} & $\begin{array}{c}\text { Fokal tanpa } \\
\text { gangguan } \\
\text { kesadaran }\end{array}$ \\
\cline { 2 - 7 } & $\mathbf{n}$ & $\mathbf{\%}$ & $\mathbf{n}$ & $\mathbf{\%}$ & $\mathbf{n}$ & $\mathbf{\%}$ \\
\hline Visuospasial/Fungsi eksekutif & 15 & $21 \%$ & 9 & $23,1 \%$ & 5 & $17,2 \%$ \\
Penamaan & 6 & $8,3 \%$ & 1 & $2,6 \%$ & 5 & $17,2 \%$ \\
Atensi & 13 & $18 \%$ & 7 & $18 \%$ & 4 & $13,8 \%$ \\
Bahasa & 8 & $11 \%$ & 5 & $13 \%$ & 4 & $13,8 \%$ \\
Abstraksi & 13 & $18 \%$ & 7 & $18 \%$ & 5 & $17,2 \%$ \\
Delayed recall & 16 & $22 \%$ & 9 & $231 \%$ & 6 & $20,7 \%$ \\
Orientasi & 1 & $1,4 \%$ & 1 & $2,6 \%$ & 0 & $0 \%$ \\
\hline
\end{tabular}

\section{BAHASAN}

Berdasarkan hasil penelitian (Tabel 1) didapatkan bahwa pasien laki-laki lebih banyak dibandingkan dengan perempuan dengan penyebab yang belum diketahui. Perbedaan ini diperkirakan disebabkan oleh hormon yang memiliki hubungan dengan epilepsy. Terdapat 2 hormon seks pada perempuan (estrogen dan progesteron) yang memengaruhi ambang kejang sampai batas tertentu. Pertimbangan lain ialah pada populasi tertentu gejala dan diagnosis epilepsi pada wanita dirahasiakan dari publik karena epilepsi bisa menjadi permasalahan dalam kehidupan sosial hingga pernikahan; hal ini juga mengurungkan niat perempuan untuk mencari pengobatan sehingga terjadi kesenjangan pera-watan dan mengarah pada gangguan-gangguan yang diakibatkan epilepsi di antaranya ialah gangguan fungsi kognitif. ${ }^{13-15}$ Berdasarkan penelitian ini didapatkan gangguan fungsi kognitif sedang (50\%).

Tabel 2 dan 4 menunjukkan bahwa pada usia 19-64 tahun banyak yang mengalami gangguan fungsi kognitif. Pada usia produktif seseorang harus menjalani pekerjaan, paparan dan bahaya saat kerja yang bisa menjadi etiologi dari epilepsi itu sendiri.. Kegiatan sehari-hari yang padat dapat menyebabkan penyandang epilepsi kekurangan jam tidur yang dapat memicu terjadinya bangkitan. ${ }^{16}$ Kekurangan tidur dapat menyebabkan seorang penyandang 
epilepsi beresiko $10 \mathrm{x}$ untuk terjadinya kejang $>1 \mathrm{x}$. Terdapat pula berbagai penyakit penyebab epilepsi seperti meningitis, dan stroke. ${ }^{17}$ Menurut Vozikis et al. ${ }^{18}$ pada pasien dengan meningitis bisa terjadi epilepsi dengan risiko sebesar 4x. Penlitian Arntz et al. ${ }^{19}$ mendapatkan bahwa setelah melakukan follow up 10 tahun terdapat $11,3 \%$ pasien yang memiliki bangkitan epilepsi paska stroke dan $39 \%$ pasien dengan epilepsi yang disertai bangkitan berulang. Di RSUP Prof Dr. R.D. Kandou Manado lebih banyak pasien usia produktif/ pertengahan yang sejalan dengan hasil penelitian ini. ${ }^{20-22}$

Berdasarkan distribusi pekerjaan pada (Tabel 1), status tidak bekerja memiliki angka tertinggi. Hal ini disebabkan oleh beberapa hal menyangkut permasalah medikolegal seperti diberhentikan dari pekerjaan karena mendapat bangkitan, meskipun bangkitan sudah terkontrol. Ditinjau dari aspek legal yang berlaku saat ini, penyandang epilepsi tidak mendapatkan akses pekerjaan, tidak ada satupun pasal menyangkut aspek perlindungan hukum. ${ }^{23}$ Walaupun demikian, pada sebagian penyandang epilepsi memang disebabkan karena mengalami disabilitas kognitif dan fungsional. Menurut Vozikis et al. ${ }^{18}$ pekerjaan yang terkait bahan kimia dapat menyebabkan epilepsi. ${ }^{18}$

Pada Tabel 1, sebagian besar penyandang epilepsi memiliki tingkat pendidikan akhir SMA $(51,5 \%)$ yang sejalan dengan penelitian lainnya yang dilakukan di Manado. ${ }^{20,21}$ Hal ini mungkin disebabkan oleh gangguan fungsi kognitif yang dialami penyandang epilepsy. Tabel 2 dan 4 menunjukkan bahwa sebagian besar pasien epilepsi mengalami gangguan fungsi kognitif sehingga mereka hanya mampu untuk melaksanakan pendidikan hingga SMA, atau tekanan tetangga dan teman yang menstigmatisasi bahwa anak tidak mampu bersekolah, membuat keengganan terhadap anak dalam melanjutkan ke jenjang selanjutnya, yang membutuhkan proses berpikir lebih, analisis, serta pemecahan masalah. ${ }^{23,24}$

Tabel 1 menunjukkan bahwa frekuensi
1-10 kali per bulan ialah yang tertinggi $(37,1 \%)$. Perempuan yang akan memasuki menopause dilaporkan mengalami peningkatan kekambuhan pada saat perimenopause. $^{23,24}$ Hal ini kemungkinan akibat peningkatan rasio estradiol terhadap progesteron. ${ }^{18}$ Menurut penelitian Rizka et al. ${ }^{25}$ pasien dengan epilepsi yang mengalami stres sebesar $70,3 \%$ dibandingkan dengan yang tidak stress sebesar 29,7\%; dalam hal ini stres berhubungan dengan kejadian terjadinya serangan bangkitan epilepsi dengan $P=<0,005$.

Epilepsi merupakan penyakit yang berkepanjangan. Dalam penelitian ini didapatkan bahwa lebih banyak pasien yang menderita $>6$ tahun $(54,3 \%)$ (Tabel 1$)$. Lama menderita $>6$ tahun mendominasi dalam gangguan fungsi kognitif (Tabel 2 dan 4). Hal ini disebabkan karena paparan bangkitan pada otak selama bertahun-tahun lamanya, melalui mekanisme eksotoksisitas, inflamasi, dan berkurangnya aliran darah hippokampal menyebabkan cedera pada otak. ${ }^{26}$ Berkepanjangannya pasien dalam menghadapi epilepsi dapat memicu depresi, yang selaras dengan penelitian Lengkoan ${ }^{27}$ bahwa terdapat $33,3 \%$ pasien yang mengalami depresi. Keadaan depresi menyebabkan defisit kognitif terutama pada atensi dan memori. ${ }^{28}$ Terjadinya peningkatan pada regio frontal dan insula dalam kondisi yang memerlukan kognitif menandakan bahwa pasien depresi perlu bekerja lebih keras karena kapasitas dasarnya untuk berpikir yang terbatas. ${ }^{29}$ Berdasarkan penelitian Jaiswal et al. ${ }^{30}$ didapatkan komorbiditas psikiatrik seperti gangguan mood (21\%), gangguan cemas (14\%), dan gangguan psikotik (28\%)

Pada penelitian ini epilepsi sekunder lebih banyak ditemukan dibandingkan dengan epilepsi primer $(57,1 \%$ vs $42,9 \%)$. Adanya kontribusi factor-faktor seperti alcohol dan trauma kepala, keduanya memiliki angka kejadian yang tinggi di Manado. Trauma kepala bertanggung jawab pada $5 \%$ epilepsi dan $20 \%$ epilepsi simtomatik. ${ }^{13}$ Hal ini sejalan dengan penelitian Yulinda et al. ${ }^{31}$ yang menyimpulkan bahwa pasien yang mengalami 
cedera kepala berhubungan secara bermakna terhadap kejadian epilepsi bangkitan umum di Poliklinik Saraf RSUD Dokter Soedarso Pontianak yakni dengan peluang 16x lebih berisiko. Berbeda dengan penelitian Wennberg et al. ${ }^{32}$, dalam suatu studi kohort skala besar, tidak ditemukan peningkatan insidens dari epilepsi dan bukan merupakan suatu faktor risiko yang bermakna dalam perkembangan epilepsi pasca trauma, setidaknya dalam satu dekade pasca trauma.

Hasil penelitian ini memperlihatkan bahwa monoterapi lebih mendominasi politerapi $(68,5 \%$ vs $31,4 \%)$ (Tabel 1$)$. Monoterapi yang sering digunakan di RSUP Prof Dr. R.D. Kandou Manado terdiri dari 3 jenis, yaitu fenitoin, asam valproat, dan karbamazepin dengan jumlah penggunaan terbanyak untuk terapi epilepsi yaitu fenitoin. ${ }^{20-22,26}$ Penggunaan monoterapi dikarenakan banyak kasus kontrol dibandingkan kasus baru sehingga telah dilakukan pengurangan jumlah obat serta dosis. Selain itu, aspek ekonomipun turut dipertimbangkan karena sejumlah besar pasien menggunakan BPJS yang menanggung ketiga obat yang terbanyak digunakan, mudahnya didapat, dan harga obat tersebut yang murah. Pada penggunaan obat anti epilepsi (OAE) lama, masih banyak ditemukan dampak terhadap gangguan fungsi kognitif bahkan bila dibandingkan OAE baru, sebagai contoh benzodiazepine. Sebagian besar OAE baru dapat mengurangi efek gangguan fungsi kognitif, kecuali topiramat yang dilaporkan masih menyebabkan gangguan fungsi kognitif. ${ }^{33}$

Pada pemeriksaan Ina-MoCA dan MMSE, didapatkan bahwa sebagian besar pasien dengan pengobatan politerapi (Tabel 2 dan 4) mengalami gangguan fungsi kognitif sedang. Efek OAE dapat meningkatkan stres oksidatif pada otak yang menyebabkan kerusakan neuronal hingga terjadinya suatu gangguan kognitif pada penyandang epilepsi. ${ }^{34}$ Efek OAE bersifat fleksibel; bila obat tersebut dihentikan maka gangguan fungsi kognitif berangsur membaik. ${ }^{33,34}$ Penyandang epilepsi harus minum obat secara rutin. Pengawasan ketat meminum obat oleh keluarga dapat membantu prognosis yang sejalan dengan penelitian yang dilakukan Oktaviana et al. ${ }^{35}$ yang meloprkan adanya hubungan kuat antara dukungan keluarga dan kepatuhan minum obat

Dalam pemeriksaan MMSE (Tabel 3), sebagian besar pasien mangalami gangguan memori diikuti dengan atensi. Demikian juga pada pemeriksaan Ina-MoCA (Tabel 5) didapatkan yang terbanyak ialah pasien epilepsi dengan gangguan memori tertunda diikuti dengan gangguan fungsi eksekutif, abstraksi, dan atensi.

Tabel 3 dan 5 memperlihatkan bahwa gangguan domain kognitif pada penyandang epilepsi, onset umum yang paling menunjukkan gangguan fungsi kognitif. Bangkitan yang difus merusak pada beberapa titik di otak secara luas dibandingkan dampak yang diakibatkan oleh bangkitan fokal baik dengan gangguan kesadaran maupun tanpa gangguan kesadaran. ${ }^{36}$

\section{SIMPULAN}

Dari hasil penelitian ini dapat disimpulkan bahwa penyandang epilepsi yang menunjukkan penurunan kognitif sebagian besar berjenis kelamin laki-laki, usia 19-64 tahun, tingkat pendidikan terakhir SMA, tidak bekerja, memiliki bangkitan >10x, durasi bangkitan $>5$ menit, lama bangkitan $>6$ tahun., onset umum, jenis epilepsi sekunder, dan menjalani pengobatan monoterapi.

Hasil pemeriksaan fungsi kognitif pada penyandang epilepsi dengan MMSE, mendapatkan $77,10 \%$ penyandang epilepsi memiliki fungsi kognitif normal tetapi dengan menggunakan Ina-MoCA didapatkan $89 \%$ mengalami gangguan fungsi kognitif ringan-sedang

\section{SARAN}

Perlu dilakukan pemeriksaan rutin MMSE dan Ina-MoCA setiap 6 bulan pada penyandang epilepsi yang berobat ke Poliklinik Neurologi RSUP Prof. Dr. R. D. Kandou Manado untuk mendeteksi dini adanya gangguan kognitif. 
Penting bagi penyandang epilepsi untuk selalu melatih fungsi kognitif.

Diperlukan penelitian observasional dengan jangka waktu yang lebih panjang dengan jumlah sampel dan variabel yang lebih besar.

\section{DAFTAR PUSTAKA}

1. Nehra A, Tripathi M, Bhatia R, Srivastana MVP, Singh MB, Copra S, et al. Is epilepsy a cause of cognitive decline in developing brain? Act Ner Super. 2013;55:112-7.

2. Murray CJ, Vos T, Lozano R, Naghavi M, Flaxman AD, Michaud $\mathrm{C}$, et al. Disability-adjusted life years (DALYs) for 291 diseases and injuries in 21 regions, 1990-2010: a systematic analysis for the global burden of disease study 2010. Lancet 2012;380:2197223.

3. Muliawan E, Floransia I, Setiawan JI, Juwita A, Stevan A, Dompas A. 10 penyakit terbanyak rawat jalan tahun 2016 RSUP Prof. Dr. R.D. Kandou Manado. SMF Neurologi RSUP Prof. Dr. R. D. Kandou, 2017.

4. Fiest KM, Birbeck GL, Jacoby A, Jette N. Stigma in epilepsy. Curr Neurol Neurosci Rep. 2014;14:444.

5. Hawari I. Epilepsi di Indonesia. 2010 [cited 2017 Dec 8]. Available from: http://www.ina-epsy.org/epilepsi-diindonesia.html.

6. Fisher PL, Noble AJ. Anxiety and depression in people with epilepsy: the contribution of metacognitive beliefs. Seizure: NEJM. 2017;50:153-9.

7. Miller L, Galioto R, Tremont G, Davis J, Bryant $\mathrm{K}$, Roth $\mathbf{J}$, et al. Cognitive impairment in older adults with epilepsy: characterization and risk factor analysis. Epil \& Behav 2016;56:113-7.

8. Wo SW, Ong LC, Low WY, Lai PSM. The impact of epilepsy on academic achievement in children with normal intelligence and without major comorbidities: a systematic review. Epil Res. 2017;136:35-45.

9. Reilly C, Atkinson P, Das KB, Chin RF, Aylett SE, Burch V, et al. Cognition in school-aged children with "active" epilepsy: a population-based study. J Clin Exp Neuropsychol. 2015;37:429-
38.

10. Ijff DM, Postulart D, Lambrechts DA, Majoie MH, de Kinderen RJ, Hendriksen JG, et al. Cognitive and Behavioral impact of the ketogenic diet in children and adolescents with refractory epilepsy: a randomized controlled trial. Epil Behav. 2016; 60:153-157.

11. Maryanti NCW. Epilepsi dan budaya. Buletin Psikologi. 2016;24(1):23-32.

12. Prasher VP, Kerr M Editors. Epilepsy and Cognition. Epilepsy and Intellectual Disabilities $\left(2^{\text {nd }}\right.$ ed). United Kingdom: Springer, 2016; p. 281-7, 291-4.

13. Shakirullah, Ali N, Khan A, Nabi M. The prevalence, incidence and etiology of epilepsy. Int J Clin \& Exp Neurol. 2014;2(2):29-39.

14. Fiest KM, Sauro KM, Wiebe S, Patten S, Kwon CS, Dykeman J, et al. Prevalence and incidence of epilepsy : a systematic review and meta-analysis of international study. Neurology. 2016; $88: 1-8$.

15. Lukas A, Harsono, Astuti. Gangguan kognitif pada epilepsi. Berkala Ilmiah Kedokteran Duta Wacana. 2016;1: 14450.

16. Hauser SL, Longo DL, Kasper DL, Fauci AS, Jameson JL, Loscalzo J, et al. Disease of the Nervous System. Harrison Neurology in Clinical Medicine (3rd ed). [e-book] McGrawHill, 2013; p. 231-44.

17. Nisa RA, Fibriani AR, Hernawan B. Hubungan antara kualitas tidur dengan frekuensi kejang pada pasien epilepsi di RSUD Dr. Moewardi Surakarta [Skripsi]. Surakarta: Universitas Muhammadiyah Surakarta; 2015.

18. Vozikis A, Goulionis JE, Nikolakis D. Risk Factors associated with epilepsy: a case-control study. Heal Sci J. 2012: 6(3):509-16.

19. Arntz R, Rutten L, Maaijwee N, Schoonderwaldt H, Dorresteijn L, van Dijk $\mathbf{E}$ et al. Post-Stroke Epilepsy in young adults: a long-term follow-up study. PLoS ONE. 2013;8(2). Available from: https://doi.org/ 10.1371/ journal.pone.0055498

20. Tendean P, Karema W, Mawuntu AHP. Gambaran penyandang epilepsi berdasarkan ILAE 1989 di Poliklinik 
Saraf RSUP Prof. Dr. R.D Kandou Manado tahun 2014. eCl. 2016;4(1).

21. Khasanah R, Mahama CN, Runtunewe T. Profil penyandang epilepsi di Poliklinik Saraf RSUP Prof Dr. R.D. Kandou Manado periode Juni 2013 - Mei 2014. eCl. 2015;3(1).

22. Hasibuan HM, Mahama CN, Tumewah R. Profil penyandang epilepsi di Poliklinik RSUP Prof. Dr. R.D. Kandou Manado periode Juli 2015 - Juni 2016. eCl. 2016;4(2).

23. Kelompok Studi Epilepsi PERDOSSI. Epidemiologi epilepsi; Definisi, klasifikasi dan etiologi epilepsi, Diagnosis dan diagnosis banding; EEG pada epilepsi. In: Kusumastuti, Gunadharma S, editors. Pedomen Tatalaksana Epilepsi (5th ed). Surabaya: Pusat Penerbitan dan Percetakan Unair (AUP), 2014; p. 1-23, 85-8.

24. Singh H, Ghacibeh GA. Epilepsy and cognition. J Autism Epil. 2016; 1(2):1006.

25. Rizka LY, Pujarini LA, Sulistyani. Hubungan antara stress dengan serangan pada pasien epilepsi di Poliklinik Saraf RSUD Dr. Moewardi [Skripsi]. Surakarta: Universitas Muhammadiyah Surakarta; 2014. Gorelick PB, Testai FD, Hankey GJ, Wardlaw JM. Epilepsy. Hankey's Clinical Neurology. 2nd Ed. [e-book] CBC Press; 2014. p. 111-5.

26. Syafii H, Indrayana Y, Amalia E. Pola Pengobatan dan fungsi kognitif pasien epilepsi di RSJ Mutiara Sukma. Jurnal Kedokteran Brawijaya. 2017;29(4): 335-40.

27. Lengkoan J, Khosama H, Sampoerno $M$. Uji Neurological Depression Disorder Inventory for Epilepsy (NDDI-E) pada pasien epilepsi di Poliklinik Saraf
RSUP Prof. R.D. Kandou. eCl. 2015;3(2).

28. Greener M. Beyond Seizures: Understanding cognitive deficits in epilepsy. Prog in Neurol and Pysch. 2013;17(3):31-2.

29. Palmer SM, Crewther SG, LM Carey. A meta-analysis of changes in brain activity in clinical depression. Front Hum Neurosci. 2015;8:1045-64

30. Jaiswal S, Kumar S, Sharma C, Kuchhal A, Jaiswal A. Psychiatric comorbidities in patiens with epilepsy: a cross sectional study. Int J Adv Integ Med Sci. 2017;2(1) 24-8.

31. Yulinda M, Roshinta D, Nawangsari. Hubungan antara riwayat cedera kepala terhadap kejadian epilepsi bangkitan umum di Poliklinik Saraf Rumah Sakit Umum Daerah Dokter Soedarso Pontianak. Jurnal Pendidikan Dokter Kalbar. 2015;3(1) [Cited 2017 Des 8]. Available from: http://jurnal.untan. ac.id/index.php/jfk/article/view/10591.

32. Wennberg R, Hiploylee $\mathbf{C}$, Tator C. Is concussion a risk factor for epilepsy? British Journal of Sports Medicine. 2017;51(11). Available from: http:// dx.doi.org/10.1136/bjsports-2016097270.64

33. Lodhi S, Agrawal N. Neurocognitive problems in epilepsy. Adv Pysch Treat. 2012;18:232-40.

34. Adams J, Jocson VA, Inoyama K, Bartlet V, Sandhu S, Oso J, et al. Methylphenidate, cognition and epilepsy. Neurology. 2016;88:1-7.

35. Oktavaian R, An A, Asroruddin M. Hubungan antara dukungan keluarga dan kepatuhan minum obat pada pasien epilepsi di RSUD Sultan Syarif Mohamad Alkadrie Kota Pontianak. Jurnal Mahasiswa PSPD FK Universitas Tanjungpura. 2017;5(1):1-9. 